\title{
The metal-nonoate Ni(SalPipNONO) inhibits in vitro tumor growth, invasiveness and angiogenesis
}

\author{
Valerio Ciccone ${ }^{1, *}$, Martina Monti ${ }^{2,3, *}$, Enrico Monzani ${ }^{3,4}$, Luigi Casella $^{3,4}$ and Lucia \\ Morbidelli ${ }^{1,3}$ \\ ${ }^{1}$ Department of Life Sciences, University of Siena, Siena, Italy \\ ${ }^{2}$ Department of Molecular Medicine and Development, University of Siena, Siena, Italy \\ ${ }^{3}$ Noxamet Ltd, Milan, Italy \\ ${ }^{4}$ Department of Chemistry, University of Pavia, Pavia, Italy \\ *These authors contributed equally to these work
}

Correspondence to: Lucia Morbidelli, email: Iucia.morbidelli@unisi.it

Keywords: nitric oxide donor; lung cancer cells; apoptosis; angiogenesis; vascular endothelial growth factor

Received: October 18, $2017 \quad$ Accepted: January 25, $2018 \quad$ Published: January 30, 2018

Copyright: Ciccone et al. This is an open-access article distributed under the terms of the Creative Commons Attribution License 3.0 (CC BY 3.0), which permits unrestricted use, distribution, and reproduction in any medium, provided the original author and source are credited.

\section{ABSTRACT}

Nitric oxide (NO) exerts conflicting effect on tumor growth and progression, depending on its concentration. We aimed to characterize the anti-cancer activity of a new NO donor, Ni(SalPipNONO) belonging to the class of metal-nonoates, in epithelial derived tumor cells, finally exploring its antiangiogenic properties. Tumor epithelial cells were screened to evaluate the cytotoxic effect of $\mathrm{Ni}$ (SalPipNONO), which was able to inhibit cell proliferation in a dose dependent manner, being more effective than the commercial DETA/NO. The human lung carcinoma cells A549 were chosen as model to study the anti-cancer mechanisms exerted by the compound. In these cells, Ni(SalPipNONO) inhibited clonogenicity and cell invasion, while promoting apoptosis. The antitumor activity was partly due to NO-cGMP dependent pathway, contributing to reduced cell number and apoptosis, and partly to the salicylaldehyde moiety and reactive oxygen species (ROS) activated ERK1/2 signaling converging on p53 dependent caspase-3 cleavage. An additional contribution by downstream cycloxygenase-2 (COX-2) derived cyclopentenones may explain the tumor inhibitory activities. As NO has been described to affect tumor angiogenesis, we checked this activity both on tumor and endothelial cell co-cultures and in Matrigel in vivo assay. Our data document that Ni(SaIPipNONO) was able to both reduce angiogenic factor expression by tumor cells acting on hypoxia inducible factor-1a (HIF-1 a) level, and endothelial cell functions related to angiogenesis. Collectively, these data confirm the potential use of NO donors and in particular Ni(SaIPipNONO) acting through multiple mechanisms, as an agent to be further developed to be used alone or in combination with conventional therapy.

\section{INTRODUCTION}

From the first studies on the effect of nitric oxide (NO) in cancer biology, this mediator emerged as a biphasic modulator, behaving both as an antineoplastic and proneoplastic stimulus [1]. The bimodal actions of NO can be explained through the duration of NO exposure, the cellular microenvironment, NO flux, tumor cell proliferation rate, occurrence of oxidizing and reducing processes [1].

The established biochemical/cellular events elicited by NO against tumor development are essentially inhibition of cell proliferation and proapoptotic events, and vascular effects including anti-angiogenesis. The 
proapoptotic events described in the literature relate to p53 upregulation and accumulation, degradation of antiapoptotic mediators, mitochondrial membrane permeability, and induction of cytochrome c release [2-4]. In cancer cells, NO released by NO donors or nitric oxide synthase (NOS) has been suggested to activate $\mathrm{p} 53$ via DNA damage by peroxynitrite $\left(\mathrm{ONOO}^{-}\right)$[5-7].

The use of NO donors can improve vascular flow, and anticancer drug delivery in hypoxic tissue, favoring the penetration of chemotherapy in tumor tissue and improving their cytotoxic effects [8-10]. Indeed, an increase in response to radiotherapy [10,11] and chemotherapy $[12,13]$ has been reported.

Tumor tissue is characterized by low oxygen tension, a condition that promotes the activation and stabilization of hypoxia inducible factor- $1 \alpha$ (HIF-1 $\alpha$ ) which, in turn, controls the transcription of vascular endothelial growth factor (VEGF), thus promoting angiogenesis, tumor growth and metastasis $[14,15]$. NO has been reported to inhibit the expression of HIF-1 $\alpha$ through the activation of HIF-1-prolyl hydroxylases and its proteasomal degradation [16-19]. NO, by reducing HIF-1 $\alpha$ dependent VEGF levels, at the end can improve the delivery of antitumor drugs, through vascular normalization and reversion of the oncotic pressure gradient [20].

Recently, a new family of metal-nonoates has been developed [21] and characterized for their potential use in cardiovascular diseases, characterized by endothelial dysfunction, obtaining a vascular protective effect at nanomolar concentrations [22, 23]. Here, we have evaluated the antitumor activity of a member of this class, Ni(SalPipNONO), assessing the antitumor efficacy in two epithelial derived tumor cells, A549 and HT29, representative of lung and colon carcinoma, respectively. $\mathrm{Ni}($ SalPipNONO) was characterized for different mechanisms related to tumor hallmarks as well as for its antiangiogenic effects on tumor and endothelial cells.

\section{RESULTS}

\section{Antitumor effects and mechanisms of action of Ni(SalPipNONO)}

To test the effect of novel NO donor, human lung carcinoma cells A549 cells were exposed for $72 \mathrm{~h}$ to $\mathrm{Ni}($ SalPipNONO) and DETA/NO used in a wide range of concentrations $(0.001-1 \mathrm{mM})$ and cell viability was assessed by the MTT assay. The experiment was performed in 0.1 and $2 \%$ FBS (Figure $1 \mathrm{~A}$ and 1B). Ni(SalPipNONO), compared with equimolar concentrations of DETA/ $\mathrm{NO}$, was more effective in reducing cell number, in particular in the range $0.1-1 \mathrm{mM}$. The $\mathrm{EC}_{50}$ for $\mathrm{Ni}($ SalPipNONO) were 0.26 and $0.37 \mathrm{mM}$ in 0.1 and $2 \%$ serum, respectively. To assess the antiproliferative effect of the nonoate, BrdU incorporation assay were performed after $24 \mathrm{~h}$ of $\mathrm{Ni}($ SalPipNONO) treatment in 0.1 and $2 \%$
FBS (Figure 2C). In both experimental conditions, the viability of A549 cells was less than $50 \%$ after exposure to $1 \mathrm{mM}$ of NO donors. These experiments show that $\mathrm{Ni}($ SalPipNONO) exerted its antiproliferative effects at doses near $0.5 \mathrm{mM}$, while at $1 \mathrm{mM}$ it revealed a cytotoxic action.

Similar results were obtained with the human colon adenocarconma cells HT29 (Supplementary Figure 1A and $1 \mathrm{~B}$ ).

When tested on normal cells, namely $\mathrm{HaCaT}$ keratinocytes, Ni(SalPipNONO) exerted antiproliferative action only on sparse cells exposed to $2 \%$ serum (Supplementary Figure 2A). Interestingly, when the nonoate was tested on confluent cells exposed to low serum concentration, a more physiological condition, it did not inhibit cell proliferation (Supplementary Figure 2B) until $1 \mathrm{mM}$ of drug.

Next, the cellular and biochemical characterization of Ni(SalPipNONO) antitumor activity was performed in A549 cells, using $0.5 \mathrm{mM}$ concentration of the NO donor and control molecules. This concentration corresponded to a significant antiproliferative effects (on proliferating tumor cells) which allowed to study biochemical effects.

Beside cytotoxic/antiproliferative activity, we have studied the capability of metal-nonoate to interfere with clonogenicity of A549 cells. Data showed that at 0.5 and 1 $\mathrm{mM}$ of Ni(SalPipNONO) the surviving fraction was reduced of $>90 \%$ with respect to basal, while DETA/NO exerted a modest, non-significant, effect (Figure 2A and 2B).

It is well known that metastasis of cancer cells involves cell invasiveness [24]. By using the Boyden chamber and gelatin coated filters, we have investigated the activity of NO donors on cell migration. As shown in Figure $2 \mathrm{C}$, the test has been carried out in the presence of low and high concentration of an unspecific chemoattractant agent, i.e. serum. In both conditions, after $18 \mathrm{~h}$ of exposure to $0.5 \mathrm{mM} \mathrm{Ni(SalPipNONO),} \mathrm{we}$ could detect halving of cells migrated across filter toward the lower chamber. The inhibitory effect of DETA/NO was evident only when cells were stimulated by a serum gradient.

From all these data, the metal-nonoate Ni(SalPipNONO) at sub-millimolar concentration showed an antiproliferative effect on lung cancer cells, accompanied by reduced clonogenicity and invasiveness.

We then evaluated the mechanisms responsible for the tumor inhibitory effects.

First, we evaluated the involvement of the classical soluble guanylate cyclase (sGC)/cGMP pathway by the use of ODQ. The preincubation with ODQ $(10 \mu \mathrm{M}, 30 \mathrm{~min}$ before Ni(SalPipNONO) only partially reverted the NO donor cytotoxic effect (Figure 3A), suggesting that other pathways or chemical components of the molecule could be responsible of the antitumor actions. Oxidative stress and ROS production have been described to contribute to the cytotoxic effect of high doses on NO, due to its 
radical nature [6, 7]. We measured ROS levels in A549 cells stimulated with the metal-nonoate in different serum concentrations by means of the fluorophore DCFH2-DA and we found a significant burst in ROS production that was abolished by NAC pretreatment (Figure 3B).

Next, to evaluate the portion of molecule responsible of cytotoxic activity, we have tested different compounds with or without the NONO or the salicylaldehyde moiety at equimolar concentration. The compounds with salicylaldehyde group exerted the greater cytotoxic action (probably due to its metabolism in salicylic acid), with a synergetic effect with NONO group (Figure 3C). Ultimately, we can speculate that both the NONO group and salicylaldehyde moiety concur to the cytotoxic action. Since the compound devoid of NONO group did not create an oxidative environment in cells (Figure 3B), a double mechanism of cytotoxic action could be hypothesized: the NONO group induces oxidative stress, and salicylaldehyde exerts an additional mechanism.

Since COX-2 derived prostanoids can influence tumor development, and inflammation is one of the tumor hallmarks [24], we have evaluated the activity of $\mathrm{Ni}($ SalPipNONO) on COX-2 protein levels. As reported in Figure 4A, COX-2 was upregulated by $0.5 \mathrm{mM}$ concentration of the metal-nonoate, but not by DETA/NO. From a mechanistic point of view, the inhibition of COX2 activity by NS398 partially reverted the metal-nonoate cytotoxic effect (Figure 4B), hypothesising that inhibitory prostanoids could contribute to antitumor activity. Indeed, cyclopentenones as $15 \mathrm{~d}-\mathrm{PGJ}_{2}$ have been reported to inhibit cell growth and induce apoptosis in various tumors [25-29]. In our tumor model, when cells were exposed to exogenous $15 \mathrm{~d}-\mathrm{PGJ}_{2}$, a dose dependent inhibition of cell chemotaxis toward 10\% serum was detected (Figure 4C), suggesting a contribution of endogenously processed inhibitory prostanoids.

The capability of NO to induce apoptosis is widely reported in literature $[1,2,5,6]$, thus to understand the mechanisms of cell number reduction promoted by $\mathrm{Ni}($ SalPipNONO), the expression of apoptotic markers was evaluated. Exposure of cells to Ni(SalPipNONO) (0.5 mM, $15 \mathrm{~min}$ ) doubled cytochrome c levels (Figure $5 \mathrm{~A})$, maybe through the reactive species generated by NO (like peroxynitrite and ROS) that cause opening of the permeability transition pore of mitochondria $[2,30]$. Moreover, it is known that ROS activate ERK1/2 [31] and

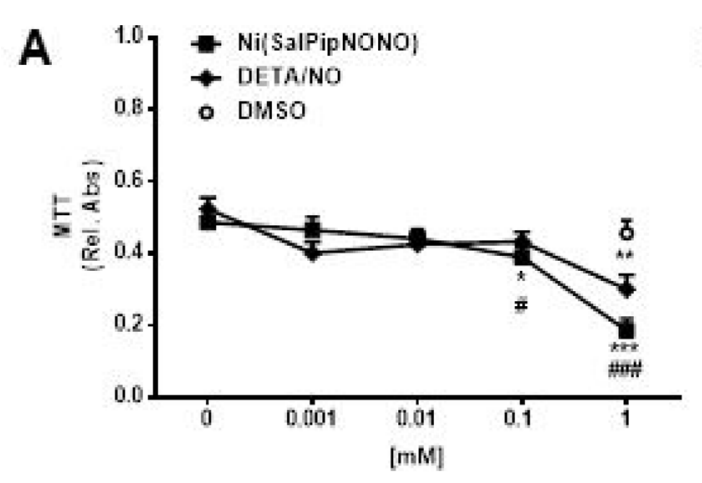

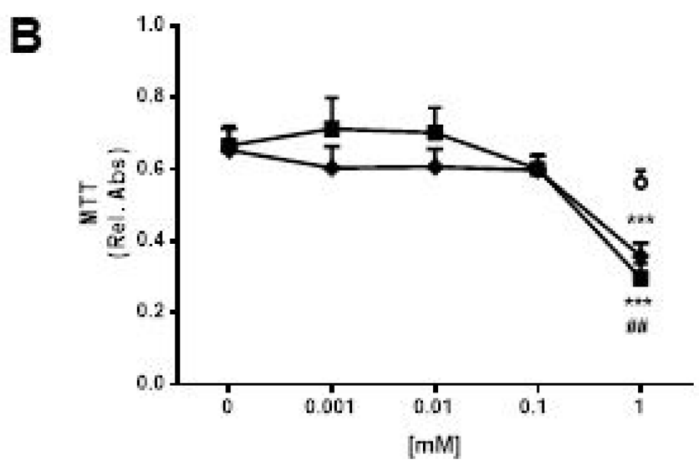

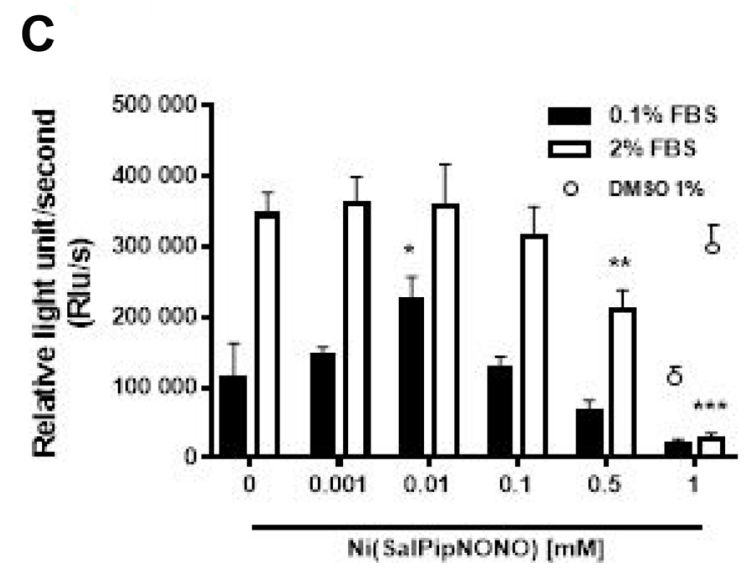

Figure 1: Ni(SalPipNONO) dose dependently inhibits tumor cell growth. A549 cells were treated with increasing concentrations of NO donors $(0.001-1 \mathrm{mM})$ in the presence of $0.1 \%(\mathbf{A})$ and $2 \%(\mathbf{B})$ serum and cell viability was evaluated by MTT after $72 \mathrm{~h}$. Data are reported as relative absorbance $\pm \mathrm{SD}(n=3)$. Cell proliferation after $24 \mathrm{~h}$ was assessed by BrdU incorporation assay $(\mathbf{C})$. Data are reported as luminescence $\pm \mathrm{SD}(n=3)$. The highest concentration of DMSO $(1 \% \mathrm{v} / \mathrm{v})$ used as vehicle was reported as control. ${ }^{*} p<0.05,{ }^{* *} p<0.01$ and ${ }^{* * *} p<0.001$ vs untreated cells. ${ }^{*} p<0.05,{ }^{\# \#} p<0.01$ and ${ }^{\# \#} p<0.001 \mathrm{Ni}($ SalPipNONO) vs DETA/NO. 
A

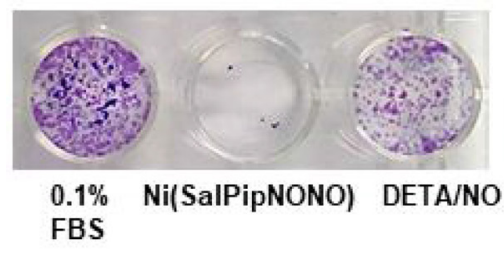

C

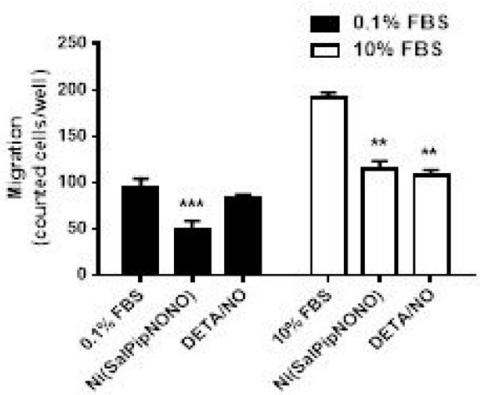

B

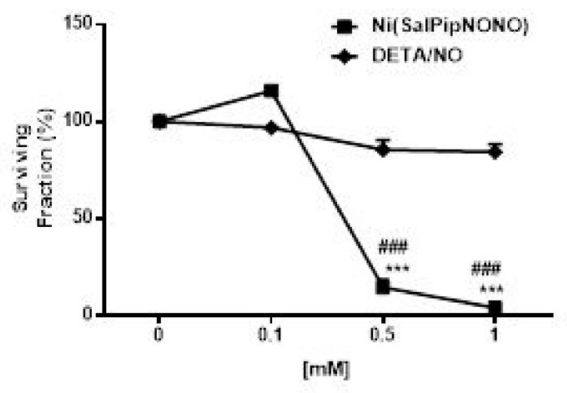

Figure 2: Ni(SalPipNONO) inhibits clonogenicity and invasiveness of A549 cells. (A) A549 monolayers were treated with test NO donors for $48 \mathrm{~h}$. After trypsinization cells were seeded at the density of 500 cells/well in 24 multi-well plates and let to form colonies for 10 days. Pictures of cultures were taken after fixation and staining. (B) The number of colonies formed by $>30$ cells were randomly counted/well and the graph represents the surviving fraction obtained giving $100 \%$ to untreated cells. $(n=3) .{ }^{* * *} p<0.001$ vs untreated cells and ${ }^{\# \#} p<0.001 \mathrm{Ni}($ SalPipNONO) vs DETA/NO. (C) Cell migration through a gelatin coated filter toward serum was assessed following incubation with $\mathrm{Ni}\left(\right.$ SalPipNONO) or DETA/NO $(0.5 \mathrm{mM})$ for $18 \mathrm{~h}$. Data are reported as number of cells counted/well. $(n=3)$. ${ }^{* *} p<0.01$ and ${ }^{* * *} p<0.001$ vs untreated cells.

A

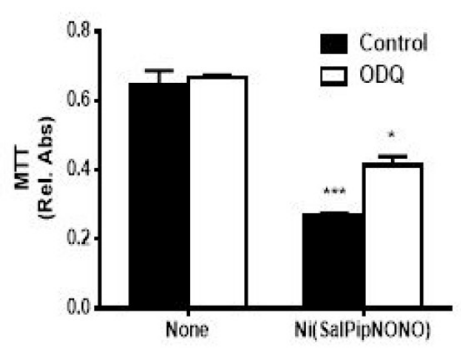

C

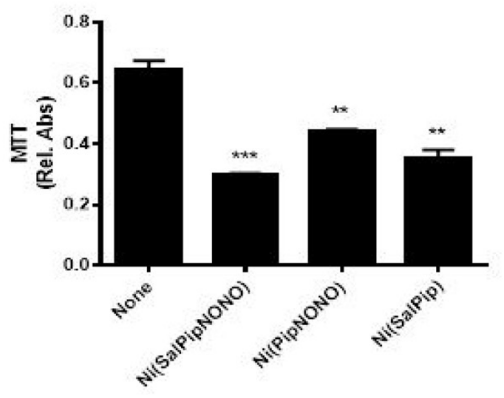

B

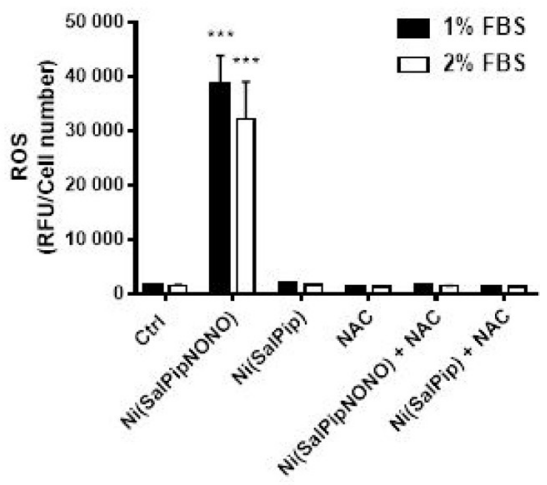

Figure 3: Molecular mechanisms responsible for cytotoxicity. (A) sGC/cGMP involvement was evaluated by the use of $10 \mu \mathrm{M}$

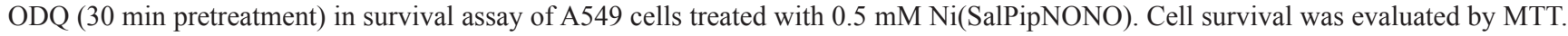
${ }^{*} p<0.05,{ }^{* * *} p<0.001$ vs untreated cells. (B) Oxidative stress involvement was assessed by measuring ROS levels in A549 cells treated with $\mathrm{Ni}(\mathrm{SalPipNONO})$ and $\mathrm{Ni}(\mathrm{SalPip}) \mathrm{Cl}$ in the presence of different serum concentrations. NAC pretreatment (5 $\mathrm{mM}, 30 \mathrm{~min})$ was used as a ROS scavenger. ${ }^{* * *} p<0.001$ vs untreated cells. (C) The contribution of NONO or salicylaldehyde moiety was evaluated by testing the cytotoxicity of molecules devoid of the NONO or salicylaldehyde group (each at $0.5 \mathrm{mM}$ ). Data are reported as relative absorbance of the MTT assay after $72 \mathrm{~h}$ incubation. ${ }^{* *} p<0.01$ and ${ }^{* * *} p<0.001$ vs untreated cells. 
in A549 cells Ni(SalPipNONO), but not DETA/NO, strongly increased pERK1/2 after 30 min of incubation (Figure 5B). ERK1/2 on its turn upregulates p53 [32-34] and in our experiments p53 maximum level was obtained after $60 \mathrm{~min}$ of incubation with the metal-nonoate (Figure 5C). Indeed, the preincubation of the cells with MEK inhibitor U0126 interfered with p53 upregulation (Figure 5D).

The ultimate event downstream to cytochrome c release is caspase 3 activation that leads to DNA cleavage and apoptosis [35]. Our data show a maximum production (triple respect basal) of cleaved-caspase 3 after $4 \mathrm{~h}$ of exposure with Ni(SalPipNONO) (Figure 5E), an effect which was completely abolished by the preincubation with the p53 inhibitor PT- $\alpha$ (Figure 5F).

From all these data it results that Ni(SalPipNONO) is able to impair cell migration and reduce cell number and survival by activating the apoptosis pathway that passes through ROS production and COX-2 cyclopentenone activation, beside the partial involvement of the $\mathrm{sGC} /$ cGMP conventional signaling.

\section{Antiangiogenic activity by Ni(SalPipNONO) on tumor and endothelial cells}

HIF-1 $\alpha$ expression and proangiogenic factor levels are correlated with an increased risk of mortality in several types of carcinoma [14]. In A549 cells, we could find

A

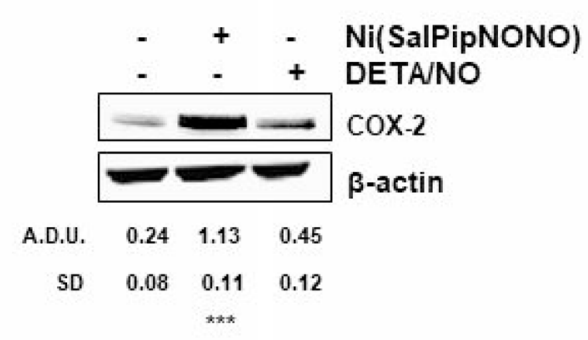

C

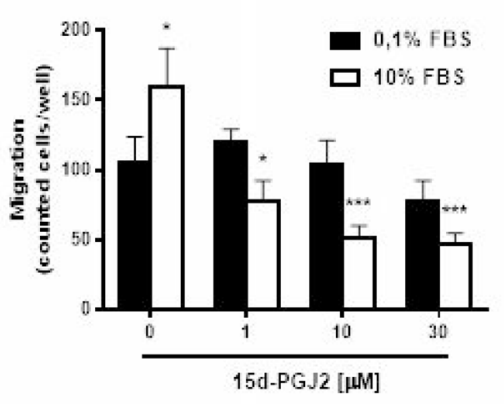

HIF-1 $\alpha$ detectable levels already in normoxic condition (Figure 6A). When A549 cells were treated for $24 \mathrm{~h}$ with $\mathrm{Ni}$ (SalPipNONO), there was a substantial decrease of HIF$1 \alpha$ expression and a consequent reduction of VEGF levels (Figure 6A). These results demonstrate that the metalnonoate reduces the angiogenetic signals in tumor cells.

We then assessed whether the antiangiogenic property was directly induced in endothelial cells. HUVEC were exposed to VEGF $(20 \mathrm{ng} / \mathrm{ml})$ in the presence of $\mathrm{Ni}($ SalPipNONO). Interestingly, at $0.1 \mathrm{mM}$ the $\mathrm{NO}$ donor completely abolished VEGF induced proliferation (Figure $6 \mathrm{~B})$. The antiangiogenic activity of $\mathrm{Ni}(\mathrm{SalPipNONO})$ was evident also in an in vivo angiogenesis assay as the subcutaneous Matrigel plug implant. After 10 days, the presence of metal-nonoate abolished the vascularization produced by VEGF, as documented by representative pictures and hemoglobin content in the plugs (Figure 6C and 6D).

Co-culture experiments with tumor and endothelial cells were set up to strengthen the above results. Endothelial cell organization on Matrigel layers was evaluated in the presence of tumor cells grown on transwell inserts and treated or not with Ni(SalPipNONO). In the presence of untreated A549, in $18 \mathrm{~h}$ HUVEC formed net-like structures, which were impaired when tumor cells were treated with the NO donor (Figure 7A). Within the same time of incubation, a reduction in VEGF expression

$\mathbf{B}$

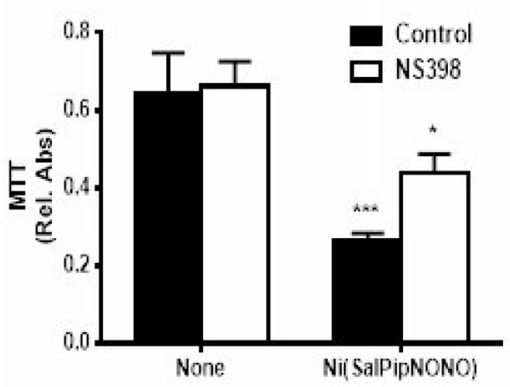

Figure 4: Ni(SalPipNONO) activates the COX-2 pathway. (A) A549 cells were treated with Ni(SalPipNONO) or DETA/NO (0.5 $\mathrm{mM}$ ) for $4 \mathrm{~h}$. COX-2 expression was evaluated by western blot. ${ }^{* * *} p<0.001$ vs untreated cells. (B) The involvement of COX-2 activity on NO donor induced cytotoxicity was evaluated by means of NS398 $(10 \mu \mathrm{M}, 30 \mathrm{~min}$ pretreatment $)$ incubation and MTT assay. ${ }^{*} p<0.05$ and ${ }^{* * *} p<0.001$ vs untreated cells. (C) Tumor cell migration toward serum was evaluated in cells treated with increasing concentrations of $15 \mathrm{~d}-\mathrm{PGJ}{ }_{2} .{ }^{*} p<0.05,{ }^{* *} p<0.01$ and ${ }^{* * *} p<0.001$ vs untreated cells. 
was observed after exposure of tumor cells to exogenous $15 \mathrm{~d}-\mathrm{PGJ}_{2}$ (Figure 7B).

These data in the whole demonstrate that the antiangiogenic activity of $\mathrm{Ni}($ SalPipNONO) is both direct on endothelial cells and indirect on tumor cells which were not able to upregulate VEGF, probably through a COX-2/ cyclopentenone dependent mechanism.

\section{DISCUSSION}

Here we describe for the first time the antitumor efficacy of novel metal-nonoates, in particular Ni(SalPipNONO) on A549 tumor cells, characterizing

\section{A}

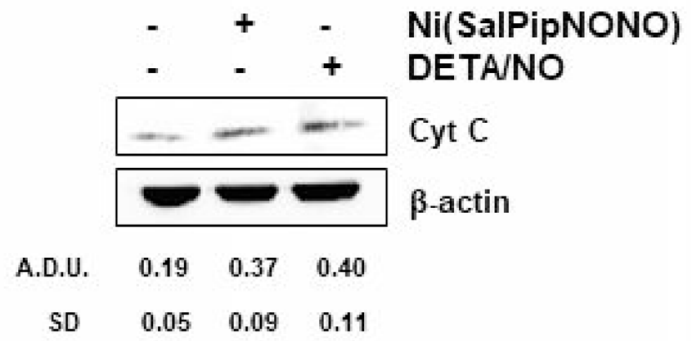

C

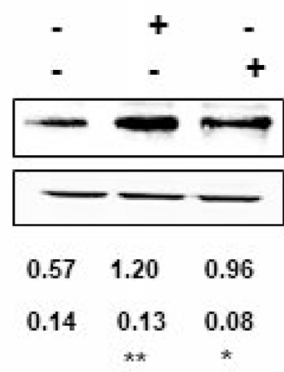

$\mathrm{Ni}($ SalPipNONO) DETA/NO

p53

$\beta$-actin

A.D.U. $\quad 0.57 \quad 1.20 \quad 0.96$

SD

$\mathbf{E}$

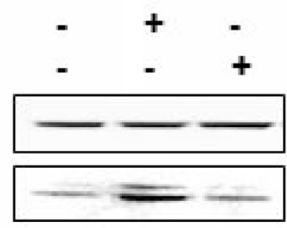

Ni(SalPipNONO)

DETA/NO

Caspase-3

Clevead-caspase-3

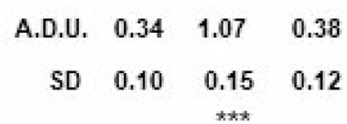

the cellular and biochemical profile of the NO donor. We have found the cytotoxic activity of $\mathrm{Ni}(\mathrm{SalPipNONO})$ at doses higher than $0.1 \mathrm{mM}$, accompanied by inhibition of tumor clonogenicity and invasiveness, hallmarks typical of malignant tumors. From a mechanistic point of view, multiple pathways are responsible for the antitumor and proapoptotic events: sGC/cGMP activation; ROS production/p-ERK1/2 and cytochrome c/p53 pathway; COX-2/cyclopentenone contribution.

The literature reports the proapoptotic effect by various NO donors in tumors, contributing to radio-, chemosensibilitazion and photodynamic therapy [36-41]. Nitroglycerin (NTG) treatment was reported to

B

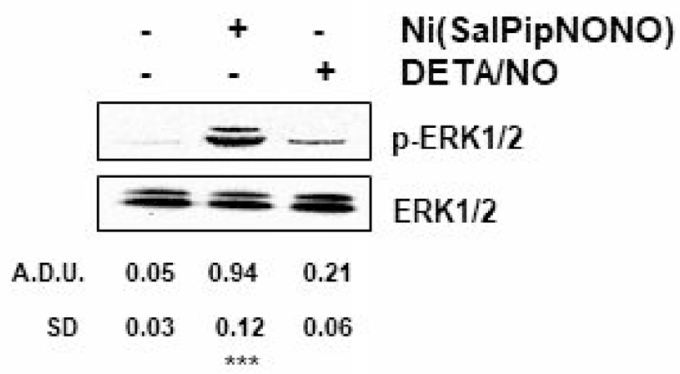

D
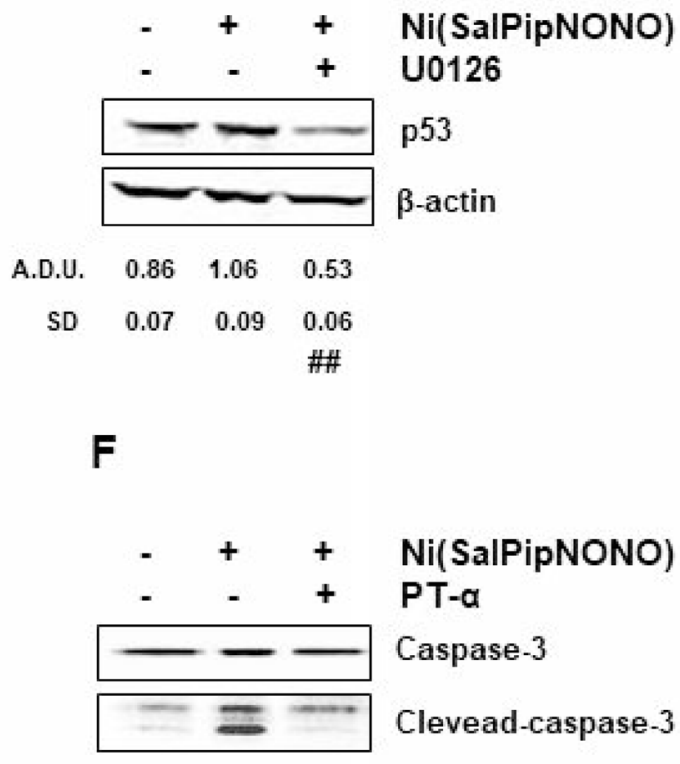

A.D.U. $\quad 0.47 \quad 1.91 \quad 0.72$

SD $\quad 0.14 \quad 0.18 \quad 0.12$

Figure 5: Ni(SalPipNONO) induces signaling related to apoptosis. A549 cells are treated with Ni(SalPipNONO) or DETA/ NO $(0.5 \mathrm{mM})$ for various times ((A) $15 \mathrm{~min}$; (B) $30 \mathrm{~min}$; (C) and (D) $1 \mathrm{~h}$; (E) and (F) $4 \mathrm{~h})$. When inhibitors (U0126 or PT- $\alpha$, each at $10 \mu \mathrm{M})$ are used, cells are pretreated for $30 \mathrm{~min}$ before stimulation with NO donors. The key signals are evaluated by western blot, using beta actin, total ERK1/2 or total caspase-3 as controls, when appropriate. Blots are representative of at least 3 with overlapping results. ${ }^{*} p<0.05$, ${ }^{* *} p<0.01$ and ${ }^{* * *} p<0.001$ vs untreated cells. ${ }^{\# \#} p<0.01$ and ${ }^{\# \#} p<0.001$ vs Ni(SalPipNONO) alone. 
significantly increase p53 phosphorylation at serine 15, and to enhance chemosensitivity to cisplatin in animal model of pathology [42]. Additional mechanisms, demonstrated following DETA/NO treatment, were S-nitrosylation and nuclear accumulation of p53 and start of intrinsic and extrinsic apoptotic pathway [43].

The influence of the conventional sGC/cGMP pathway is only marginal, since the block of the cascade with ODQ only partially reverted the cytotoxic effect of the metal-nonoate.

Here we demonstrate that Ni(SalPipNONO) promotes ERK1/2 phosphorylation, possibly through NO associated-ROS production. NO-induced oxidative

\section{A}

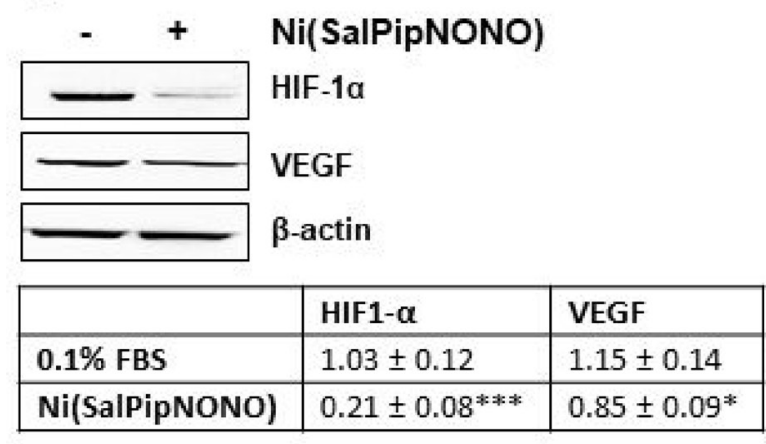

C

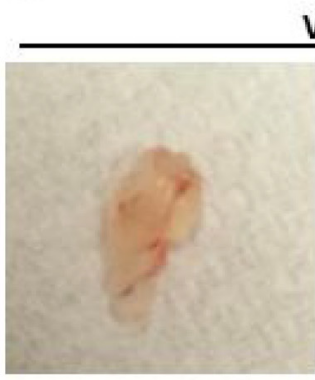

VEGF

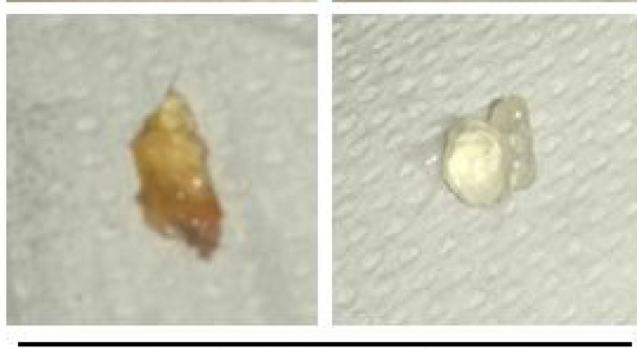

VEGF+ Ni(SalPipNONO) stress influences MAPK dependent p53 upregulation and activation ultimately leading to caspase-3 cleavage. This effect is typical of Ni(SalPipNONO), since DETA/ NO has lower capability to activate the MAPK pathway and apoptosis signalling and the compound devoid of the NONO group does not elicit an oxidative burst.

It is known that ROS mediated activation of ERK1/2 is able to activate the apoptotic pathway by antitumor agents [31]. ERK is part of the MAPK superfamily, and is well known for its ability to control cell survival in response to external stimuli $[33,44]$. Several reports have found more complex roles for ERK pathway, in which the increase of ERK activity might promote apoptosis in

\section{B}

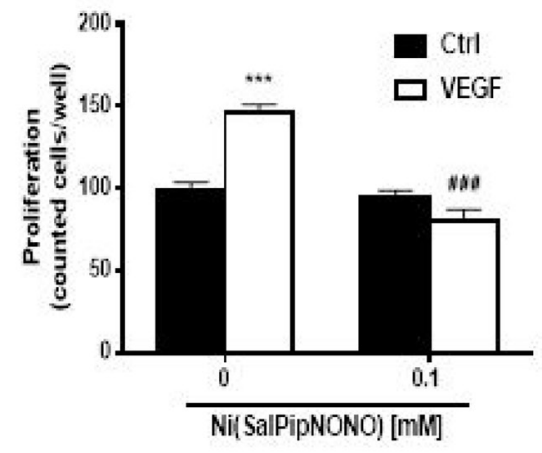

D

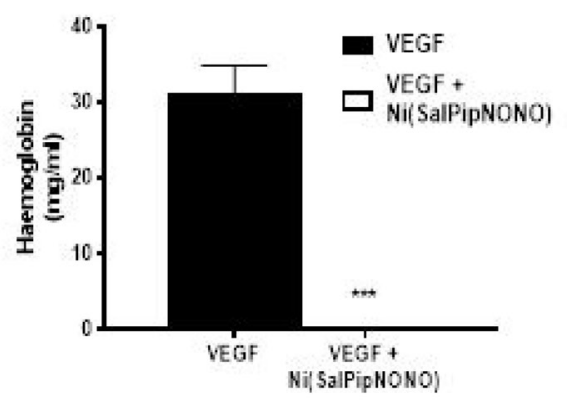

Figure 6: Ni(SalPipNONO) has antiangiogenic activities. (A) A549 cells were treated with Ni(SalPipNONO) $0.5 \mathrm{mM}$ for 24 $\mathrm{h}$ and HIF-1 $\alpha$ and VEGF protein expression was evaluated by western blot. ${ }^{*} p<0.05$ and ${ }^{* * *} p<0.001$ vs untreated cells. (B) Direct antiagiogenic activity of Ni(SalPipNONO) on cultured endothelial cells. HUVEC were treated with VEGF (20 ng/ml) in the absence/ presence of Ni(SalPipNONO) $0.1 \mathrm{mM}$. The number of cells was counted after $48 \mathrm{~h}$ following cell fixation and staining. ${ }^{* * *} p<0.001 \mathrm{vs}$ untreated cells. ${ }^{\# \#} p<0.01$ vs VEGF alone. (C) Ni(SalPipNONO) exerts antiangionic activity in vivo. Mice were subcutaneously implanted

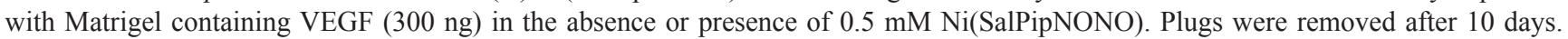
Pictures are representative plugs out of 3 , while the graph (D) reports hemoglobin content quantified by Drabkin reagent $(n=3$ plugs). ${ }^{* * *} p<0.001$ vs VEGF alone. 
specific environments. Protein kinase pathways such as the MAPK pathway are major oxidative stress-sensitive pathways in most cell types [45]. In particular, ERK is selectively activated in neuronal and renal epithelial cells upon exposure to oxidative stress and toxic agents such as cisplatin, and inhibition of the ERK pathway has been reported to block apoptosis [46]. Several studies have reported that curcumin potentiates ROS-dependent ERK activation and lethality in irradiated human cervical tumor cells [47] and that cisplatin-induced ERK activation is partly mediated through ROS generation [48]. In the current study, nonoate treatment induces a ROS burst and significantly increases ERK1/2 phosphorylation in A549 cancer cells. These results seem to be consistent with several earlier studies, in which increased ERK activity by reactive nitrogen species was linked to the induction of cell death [49].

The inhibitor of p53 PT- $\alpha$ blocked the apoptosome-mediated processing and activation of caspase- 9 and -3 without interfering with the activation of mitochondria [50]. Our data show that apoptosis occurs via a p53-dependent mechanism that takes place upstream of mitochondria and involves cytochrome c release. Indeed, it is known that the reactive species generated by high levels of NO (both peroxynitrite and
ROS) cause opening of the permeability transition pore of mitochondria [2,30].

We have then evaluated the contribution of endogenous prostanoid pathway in the anti-tumor and antiangiogenic effect of the metal-nonoate.Among the COX-2 derived prostanoids, the pro-inflammatory $\mathrm{PGE}_{2}$ has a predominant role in promoting tumor growth [51]. However, both LOX-and COX-derived products can act as endogenous ligands of anti-proliferative and antitumorigenic receptor(s), as PPAR- $\gamma$. The cyclopentenone prostaglandins $\mathrm{PGA}_{2}, \mathrm{PGA}_{1}$, and $\mathrm{PGJ}_{2}$ are formed by dehydration within the cyclopentane ring of $\mathrm{PGE}_{2}, \mathrm{PGE}_{1}$, and $\mathrm{PGD}_{2} . \mathrm{PGJ}_{2}$ is metabolized further to yield D12$\mathrm{PGJ}_{2}$ and 15-deoxy-D12,14-PGJ 2 (15d-PGJ ${ }_{2}$ ). Various compounds within the cyclopentenone prostaglandin family possess potent anti-inflammatory, anti-neoplastic, and anti-viral activity. Among cyclopentenones, $15 \mathrm{~d}_{-} \mathrm{PGJ}_{2}$ has attracted our attention.15d-PGJ ${ }_{2}$, given exogenously, reproduces the antitumor activity of the metal-nonoate. $15 \mathrm{~d}_{-} \mathrm{PGJ}_{2}$ has been show to inhibit angiogenesis via suppression of pro-inflammatory enzymes and cytokines, even if stimulatory functions on tumor angiogenesis have been reported [52]. In human umbilical vein endothelial cells $15 \mathrm{~d}-\mathrm{PGJ}$, induced apoptosis via PPAR $\gamma$-dependent mechanisms [53].
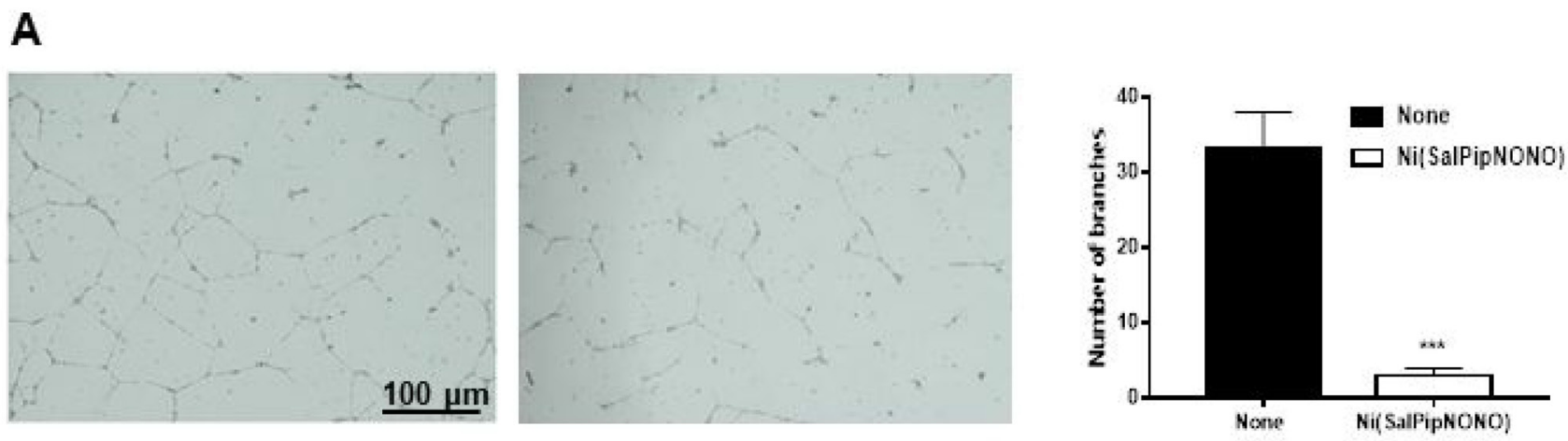

B

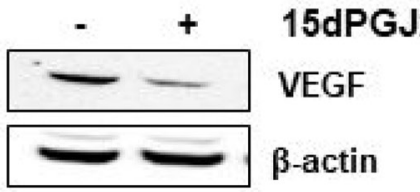

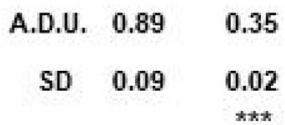

Figure 7: Ni(SalPipNONO) exerts antiangiogenic activity in a co-culture system. (A) A549 cells were seeded on transwell inserts and treated or not with $0.5 \mathrm{mM} \mathrm{Ni}($ SalPipNONO) for $54 \mathrm{~h}$. Then the inserts (with tumor conditioned medium) were transferred on multiplates with HUVEC seeded on top of a Matrigel layer. Incubation continued with further $18 \mathrm{~h}$. Pictures of HUVEC network were taken [a. medium conditioned by not treated A549; b. medium conditioned by A549 treated with Ni(SalPipNONO)] and are representative of 3 experiments. (B) Expression of VEGF by tumor cells exposed for $8 \mathrm{~h}$ to $10 \mu \mathrm{M} 15 \mathrm{~d}-\mathrm{PGJ}_{2}$. The blot is representative of 3 with similar results. ${ }^{* * *} p<0.001$ vs untreated cells. 
The cyclopentenone involvement leads us to investigate the mechanisms related to the antiangiogenic activity of the metal-nonoate. Our in vitro and in vivo results document the antiangiogenic activity of $\mathrm{Ni}($ SalPipNONO). Interestingly, the antiangiogenic activity of Ni(SalPipNONO) is both direct on endothelial cells and indirect on tumor cells via upregulation of VEGF. In the first ones it directly abrogates VEGF induced proliferative effect, while in tumor cells the nonoate inhibits HIF-1 $\alpha$ dependent VEGF upregulation. An additional contribution of cyclopentenones as $15 \mathrm{~d}_{-} \mathrm{PGJ}_{2}$ in preventing VEGF expression is here demonstrated.

A direct antiangiogenic activity by exogenous NO has been reported with other NO donors. In vitro assay with cultured endothelial cells revealed that the $\mathrm{NO}$ hybrid compound NCX-4016, significantly inhibited angiogenesis in a dose-dependent manner, with almost complete inhibition at a $100 \mu \mathrm{M}$ concentration [54]. And recently, alteration of the expression of angiogenic genes has been described in hepatoma cells in response to NO donors, in particular an increase in thrombospondin-1 and tissue inhibitors of metalloprotease-1 [55], known inhibitors of angiogenesis and tumor cell migration.

In conclusion, these data confirm the potential use of NO donors and in particular Ni(SalPipNONO) acting through multiple mechanisms, as chemotherapeutic agents to be further developed in order to be used alone or in combination with anticancer conventional therapy. The results of a randomized phase II clinical trial have been reported, documenting the feasibility of the concurrent use of NTG with chemotherapy and radiotherapy in locally advanced non-small cell lung cancer to increase chemoand radiosensitivity with an acceptable toxicity profile [56]. Interestingly, the overall survival was associated to reduced levels of circulating VEGF. Accordingly, a retrospective study suggested that application of NTG plus docetaxel and carboplatin in patients with operable lung adenocarcinoma increases the response with decreased expression of HIF-1 $\alpha$ and VEGF [57], supporting an antiangiogenic activity.

\section{MATERIALS AND METHODS}

\section{Drugs used}

The metal-nonoates Ni(SalPipNONO), $\mathrm{Ni}($ PipNONO)Cl and Ni(SalPip)Cl have been synthetized and characterized by Noxamet Ltd (Milan, Italy) as previously reported [21]. DETA/NO was from SigmaAldrich (St. Louis, MO, USA). All NO donors and control compounds were dissolved in DMSO (100 mM solution). Matrigel (growth factors and phenol red-free) was from Becton Dickinson (Waltham, MA, USA). VEGF was from R\&D Systems (Minneapolis, MN, USA). The cyclopentenone prostaglandin 15-deoxy-D12,14prostaglandin J2 (15d-PGJ ${ }_{2}$ ) was from Cayman Chemical (Ann Arbor, MI, USA).
The cyclic pifithrin-alpha (PT- $\alpha$, a cell permeable and potent p53 transcriptional inhibitor) [50] was from Sigma Life Science (Milan, Italy). The MEK inhibitor U0126 (1,4-diamino-2,3-dicyano1,4-bis(2-aminophenylthio)butadiene) and NS398, a cycloxygenase-2 (COX-2) inhibitor, were from Calbiochem (Milan, Italy). N-acetyl-L-cysteine (NAC) was from Sigma-Aldrich (St. Louis, MO, USA).

\section{Cell cultures}

The human lung carcinoma A549 cells were obtained from European Collection of Cell Cultures (Salisbury, UK). HT-29, the human colorectal adenocarcinomacells, were obtained from the American Type Culture Collection. HaCaT immortalized human keratinocytes were chosen as human normal cell controls. $\mathrm{HaCaT}$ cells (passages 3-7) were acquired from Voden Medical (Meda, MB, Italy). Cells were maintained in DMEM (Sigma-Aldrich) supplemented with 10\% fetal bovine serum (FBS) (Hyclone, Celbio, Milan, Italy) and $2 \mathrm{mM}$ glutamine, 100 units penicillin and $0.1 \mathrm{mg} / \mathrm{l}$ streptomycin (Sigma Aldrich, St. Louis, MO, USA).

Human umbilical vein endothelial cells (HUVEC) were purchased from Promocell (Heidelberg, Germany) and were grown in endothelial growth medium (EGM-2), containing VEGF, $\mathrm{R}^{3}$-IGF-1, hEGF, hFGF, hydrocortisone, ascorbic acid, heparin and GA-1000 (Lonza, Basel, Switzerland), 10\% FBS and 2 mM glutamine, 100 units/ $\mathrm{ml}$ penicillin and $0.1 \mathrm{mg} / \mathrm{ml}$ streptomycin (Sigma Aldrich, St. Louis, MO, USA). Cells were split 1:3 twice a week, and used until passage 10 . Cells were cultured at $37^{\circ} \mathrm{C}$ in $5 \% \mathrm{CO}_{2}$.

\section{MTT assay}

Tumor cell survivalwas quantified by MTT assay. $3 \times 10^{3}$ cells were seeded in 96-multiwell plates in medium with $10 \%$ serum and after adherence were exposed to $\mathrm{Ni}($ SalPipNONO) or DETA/NO (0.001 to $1 \mathrm{mM}, 72 \mathrm{~h})$ in $0.1 \%$ or $2 \%$ FBS. Where indicated, cells were pre-treated with $1 \mathrm{H}-[1,2,4]$ oxadiazolo[4,3-a]quinoxalin-1-one (ODQ) $(10 \mu \mathrm{M})$ and NS398 $(10 \mu \mathrm{M})$. Medium was removed and cells were incubated for $4 \mathrm{~h}$ with fresh medium in the presence of $1.2 \mathrm{mM}$ 3-(4,5-dimethylthiazol-2-yl)-2,5diphenyltetrazolium bromide (MTT). After solubilization in DMSO, absorbance was measured with a microplate absorbance reader (Infinite 200 Pro, Tecan Life Sciences, Switzerland) at $540 \mathrm{~nm}$. Data are reported as $540 \mathrm{~nm}$ relative absorbance/well [58].

\section{BrdU incorporation assay}

Cell proliferation was determined by 5-bromo2'-deoxy-uridine (BrdU) incorporation using a chemioluminescence ELISA according to the manufacturer's instructions (\#11669915001 Roche 
Diagnostic S.p.A, Monza, Italy). To evaluate the effect on A549 cells, $3 \times 10^{3}$ cells were seeded in 96-well plate. After adherence, cells were treated with $\mathrm{Ni}(\mathrm{SalPipNONO})$ ( 0.1 to $1 \mathrm{mM}, 24 \mathrm{~h}$ ) in presence of $0.1 \%$ e $2 \%$ FBS. To assay the effect on non-tumor cells on a condition of quiescence (to mimic a physiologic environment) $5 \times 10^{3}$ cells were seeded in 96-well plate. After adherence, cells were treated with $\mathrm{Ni}(\mathrm{SalPipNONO})$ at 0.5 and 1 $\mathrm{mM}$ for $24 \mathrm{~h}$ in presence of $0.1 \% \mathrm{FBS}$. Finally, to test the antiproliferative action of drug on non-tumor cells, $3 \times$ $10^{3}$ cells were seeded in 96-well plate. After adherence, cells were treated with $\mathrm{Ni}(\mathrm{SalPipNONO})$ at 0.5 and 1 $\mathrm{mM}$ for $24 \mathrm{~h}$ in presence of $2 \%$. FBS. In all experimental conditions BrdU was added for the last $8 \mathrm{~h}$ of incubation. Then, cells were processed following manufacturer's protocol. Chemiluminescence generated by BrdU labelled cells was measured using Infinite F200 Pro (Tecan Life Sciences, Switzerland).

\section{Clonogenic assay}

The potential cytotoxic effect of NO donors was evaluated by the clonogenic assay [59]. A549 $\left(2 \times 10^{5}\right.$ cells/well) were seeded in 6-well plates. After adherence, cells were treated with $\mathrm{Ni}(\mathrm{SalPipNONO})$ or DETA/NO ( 0.1 to $1 \mathrm{mM}, 48 \mathrm{~h}$ ). Then, cells were trypsinized, seeded in 24 multi-well plate at the density of 500 cells/well and incubated at $37^{\circ} \mathrm{C}$ for 10 days in medium with $1 \%$ serum. Colonies were fixed with methanol and stained with a solution of Cristal Violet in 10\% methanol (Sigma Aldrich, St. Louis, MO, USA). Colonies formed by over 30 cells were counted and representative pictures were shown. Data are expressed as surviving fraction.

\section{Invasion assay}

Cell invasion was performed by the Boyden chamber technique (Neuroprobe 48 -well microchemotaxis chamber) (BiomapSnc, Agrate B.za, MI, Italy), with the filter coated with gelatin (Sigma Aldrich, St. Louis, MO, USA) $[58,59] .1 .25 \times 10^{4}$ cells (A549) previously treated with $\mathrm{Ni}$ (SalPipNONO) or DETA/NO $(0.5 \mathrm{mM}, 18 \mathrm{~h})$ or $15 \mathrm{~d}_{-P G J}(1-30 \mu \mathrm{M})$ were added to the upper wells of the chamber. Lower wells contained $0.1 \%$ or $10 \%$ FBS as chemoattractant. After $4 \mathrm{~h}$ of incubation, cells were fixed and stained with Diff-Quik kit (Biomap Snc, Agrat B.za, MI, Italy). Migrated cells present in 5 fields/well were counted at $40 \times$ original magnification. Data are reported as the number of countedcells/well.

\section{ROS measurement}

ROS levels were evaluated as previously reported [60]. A total of $1.5 \times 10^{3}$ cells were seeded in 96-well plates and, after adherence, were treated with $0.5 \mathrm{mM}$ $\mathrm{Ni}($ SalPipNONO) or $\mathrm{Ni}$ (SalPip) in medium without phenol red and different serum concentrations. NAC
(5 mM, 30 min pretreatment) was used as a ROS scavenger. DCFH2-DA (2,-7-dichlorodihydrofluorescein diacetate; Invitrogen, Milan, Italy) was added (10 $\mu \mathrm{M}, 30$ $\mathrm{min}$ ) and intracellular levels of ROS were evaluated with a microplate reader (excitation/emission 495/527; Infinite F200 Pro (TecanLifeSciences, Switzerland). The results are reported as relative fluorescence units (RFU) corrected for the cell number counted.

\section{Western blot}

Sub-confluent A549 were seeded in $6 \mathrm{~cm}$ diameter Petri dishes. After adherence, cells were treated for the indicated times with $\mathrm{Ni}(\mathrm{SalPipNONO})(0.5 \mathrm{mM})$ and specific pathway inhibitors. Protein extraction and Western blot were performed as previously described $[58,61]$. Electrophoresis (50 $\mu \mathrm{g}$ of protein/sample) was carried out in 4-12\% Bis-Tris Gels (Life Technologies, Carlsbad, CA, USA). Proteins were then blotted onto nitrocellulose membranes, incubated overnight with primary antibodies [Anti-cytochrome c, anti-phosphoERK1/2, anti-caspase- 3, anti-ERK antibodies from Cell Signaling (Celbio, Milan, Italy); anti-p53 antibody from Santa Cruz Biotechnology Inc (Dallas TX, USA); antiCOX-2 from Cayman Chemical (Ann Arbor, MI, USA); anti-HIF-1 $\alpha$ from BD Biosciences (San Jose, CA, USA); anti-VEGF from Merck KGaA (Darmstadt, Germany)] and then detected by enhanced chemiluminescence system (Biorad, Hercules, CA, USA). Results were normalized to those obtained by using an antibody against beta actin from Merck KGaA (Darmstadt, Germany) or total ERK1/2 (Cell Signaling, Celbio, Milan, Italy), when indicated.

\section{Endothelial survival assay}

Survival of endothelial cells (HUVEC) was evaluated following the protocol previously reported [61]. $1 \times 10^{3} \mathrm{cells} /$ well (of 96-well multiplates) were let to adhere in 10\% serum for 3-4 $\mathrm{h}$ and then VEGF $(20 \mathrm{ng} / \mathrm{ml})$ in presence/absence of the NO donor was added in medium with $0.1 \%$ serum. After 2 days, cells were fixed, stained and randomly counted at $20 \times$ original magnification in 5 fields. Data are reported as number of cell counted/well.

\section{In vitro co-culture assay}

Tumor cells $\left(3 \times 10^{4}\right.$ cells $)$ were cultured on transwell inserts $(12 \mathrm{~mm}$ diameter, polycarbonate membranes with $0.4 \mu \mathrm{m}$ pores; Corning, Lowell, MA, USA) and treated for $24 \mathrm{~h}$ with $0.5 \mathrm{mM} \mathrm{Ni}$ (SalPipNONO). Then the inserts were transferred on top of endothelial cells plated on Matrigel $\left(1.5 \times 10^{5}\right.$ cells in 12 -well multiplate) for further $18 \mathrm{~h}$ of incubation. At the end of the experiment, endothelial cells were photographed and network formation on Matrigel was measured by means of the number of complete circles (Nikon Eclipse E400 and camera Nikon DS-5MC). 


\section{In vivo matrigel angiogenesis assay}

Investigation has been conducted in accordance with the ethical standards and according to the Declaration of Helsinki and the Italian law (Legislative Decree no.26, 4 March 2014), which acknowledges the European Directive 2010/63/UE, being approved by the authors' institutional review board and the Italian Ministry of Health. All efforts were made to minimize the number of animals used and their suffering. In vivo Matrigel angiogenesis assay was performed as previously described [32]. C57 black mice (20-25 g) were kept in temperature- and humiditycontrolled rooms (at $22^{\circ} \mathrm{C}$ ) with lights on from 7 am to $7 \mathrm{pm}$, water and food available ad libitum. VEGF (300 ng) in presence/absence of Ni(SalPipNONO) $(0.5 \mathrm{mM})$ was diluted in growth factor and phenol red-free Matrigel (Becton Dickinson, Franklin Lakes, NJ, USA) on ice. Mice were subcutaneously injected in the dorsal midline region with $0.4 \mathrm{ml}$ of Matrigel. After 10 days, mice were euthanized and implants harvested. Plugs were re-suspended in $1 \mathrm{ml}$ of Drabkin's reagent (Sigma Aldrich, St. Louis, MO, USA) for $18 \mathrm{~h}$ on ice and hemoglobin concentration was determined by absorbance at $540 \mathrm{~nm}$ and compared with a standard curve (Sigma Aldrich, St. Louis, MO, USA).

\section{Statistical analysis}

Data represent means $\pm \mathrm{SD}$ of at least 3 determinations. Statistical analysis was performed by means of Student's $t$ test for unpaired data or by analysis of variance, followed by Bonferroni's test for comparison among groups of data; $p<0.05$ was considered statistically significant.

\section{Abbreviations}

cycloxygenase-2 (COX-2); 15-deoxy-D12,14prostaglandin J2 (15d-PGJ2); 2,-7-dichlorodihydrofluorescein diacetate (DCFH2-DA); fetal bovine serum (FBS); human umbilical vein endothelial cells (HUVEC); hypoxia inducible factor-1 $\alpha$ (HIF-1 $\alpha$ ); (3-(4,5-dimethylthiazol-2-yl)-2,5diphenyltetrazolium bromide) (MTT); N-acetyl-L-cysteine (NAC); nitric oxide (NO); nitric oxide synthase (NOS); nitroglycerin (NTG); 1H-[1,2,4]oxadiazolo[4,3-a]quinoxalin1-one (ODQ); pifithrin-alpha (PT- $\alpha$ ); reactive oxygen species (ROS); relative fluorescence units (RFU); soluble guanylate cyclase (sGC); vascular endothelial growth factor (VEGF).

\section{ACKNOWLEDGMENTS}

This work was partially funded by MIUR-PRIN project n. 2015Y3C5KP to LM.

\section{CONFLICTS OF INTEREST}

None.

\section{REFERENCES}

1. Burke AJ, Sullivan FJ, Giles FJ, Glynn SA. The yin and yang of nitric oxide in cancer progression. Carcinogenesis. 2013; 34:503-12.

2. Boyd CS, Cadenas E. Nitric oxide and cell signaling pathways in mitochondrial-dependent apoptosis. Biol Chem. 2002; 383:411-23.

3. Sarti P, Forte E, Mastronicola D, Giuffrè A, Arese M. Cytochrome c oxidase and nitric oxide in action: molecular mechanisms and pathophysiological implications. Biochim Biophys Acta. 2012; 1817:610-9.

4. Huerta-Yepez S, Baritaki S, Baay-Guzman G, HernandezLuna MA, Hernandez-Cueto A, Vega MI, Bonavida B. Contribution of either YY1 or BclXL-induced inhibition by the NO-donor DETANONOate in the reversal of drug resistance, both in vitro and in vivo. YY1 and BclXL are overexpressed in prostate cancer. Nitric Oxide. 2013; 29:17-24.

5. Schneiderhan N, Budde A, Zhang Y, Brüne B. Nitric oxide induces phosphorylation of $\mathrm{p} 53$ and impairs nuclear export. Oncogene. 2003; 22:2857-68.

6. Kim PK, Zamora R, Petrosko P, Billiar TR. The regulatory role of nitric oxide in apoptosis. Int Immunopharmacol. 2001; 1:1421-41.

7. Porasuphatana S, Tsai P, Rosen GM. The generation of free radicals by nitric oxide synthase. Comp Biochem Physiol C Toxicol Pharmacol. 2003; 134:281-9.

8. Liu YS, Chuang MT, Tsai YS, Tsai HM, Lin XZ. Nitroglycerin use in transcatheter arterial (chemo) embolization in patients with hepatocellular carcinoma and dual-energy CT assessment of Lipiodol retention. Eur Radiol. 2012; 22:2193-200.

9. Seki T, Fang J, Maeda H. Enhanced delivery of macromolecular antitumor drugs to tumors by nitroglycerin application. Cancer Sci. 2009; 100:2426-30.

10. Jordan BF, Beghein N, Aubry M, Grégoire V, Gallez B. Potentiation of radiation-induced regrowth delay by isosorbide dinitrate in FSaII murine tumors. Int J Cancer. 2003; 103:138-41.

11. Jordan BF, Misson P, Demeure R, Baudelet C, Beghein N, Gallez B. Changes in tumor oxygenation/perfusion induced by the no donor, isosorbide dinitrate, in comparison with carbogen: monitoring by EPR and MRI. Int J Radiat Oncol Biol Phys. 2000; 48:565-70.

12. Yasuda H, Nakayama K, Watanabe M, Suzuki S, Fuji H, Okinaga S, Kanda A, Zayasu K, Sasaki T, Asada M, Suzuki T, Yoshida M, Yamanda S, et al. Nitroglycerin treatment may enhance chemosensitivity to docetaxel and carboplatin in patients with lung adenocarcinoma. Clin Cancer Res. 2006; 12:6748-57.

13. Nagai H, Yasuda H, Hatachi Y, Xue D, Sasaki T, Yamaya M, Sakamori Y, Togashi Y, Masago K, Ito I, Kim YH, Mio T, Mishima M. Nitric oxide (NO) enhances 
pemetrexed cytotoxicity via NO-cGMP signaling in lung adenocarcinoma cells in vitro and in vivo. Int J Oncol. 2012; 41:24-30.

14. Semenza GL. Targeting HIF-1 for cancer therapy. Nat Rev Cancer. 2003; 3:721-32.

15. Shinojima T, Oya M, Takayanagi A, Mizuno R, Shimizu $\mathrm{N}$, Murai M. Renal cancer cells lacking hypoxia inducible factor (HIF)-1alpha expression maintain vascular endothelial growth factor expression through HIF-2alpha. Carcinogenesis. 2007; 28:529-36.

16. Sogawa K, Numayama-Tsuruta K, Ema M, Abe M, Abe H, Fujii-Kuriyama Y. Inhibition of hypoxia-inducible factor 1 activity by nitric oxide donors in hypoxia. Proc Natl Acad Sci USA. 1998; 95:7368-73.

17. Wang X, Martindale JL, Holbrook NJ. Requirement for ERK activation in cisplatin-induced apoptosis. J Biol Chem. 2000; 275:39435-43.

18. Hagen T, Taylor CT, Lam F, Moncada S. Redistribution of intracellular oxygen in hypoxia by nitric oxide: effect on HIF1alpha. Science. 2003; 302:1975-8.

19. Díez I, Calatayud S, Hernández C, Quintana E, O’Connor JE, Esplugues JV, Barrachina MD. Nitric oxide, derived from inducible nitric oxide synthase, decreases hypoxia inducible factor-1alpha in macrophages during aspirininduced mesenteric inflammation. Br J Pharmacol. 2010; 159:1636-45.

20. Sorensen AG, Batchelor TT, Zhang WT, Chen PJ, Yeo P, Wang M, Jennings D, Wen PY, Lahdenranta J, Ancukiewicz M, di Tomaso E, Duda DG, Jain RK. A "vascular normalization index" as potential mechanistic biomarker to predict survival after a single dose of cediranib in recurrent glioblastoma patients. Cancer Res. 2009; 69:5296-300.

21. Ziche M, Donnini S, Morbidelli L, Monzani E, Roncone R, Gabbini R, Casella L. Nitric oxide releasing metaldiazeniumdiolate complexes strongly induce vasorelaxation and endothelial cell proliferation. ChemMedChem. 2008; 3:1039-47.

22. Monti M, Solito R, Puccetti L, Pasotti L, Roggeri R, Monzani E, Casella L, Morbidelli L. Protective effects of novel metal-nonoates on the cellular components of the vascular system. J Pharmacol Exp Ther. 2014; 351:500-9.

23. Monti M, Ciccone V, Pacini A, Roggeri R, Monzani E, Casella L, Morbidelli L. Anti-hypertensitive property of a nickel-piperazine/NO donor in spontaneously hypertensive rats. Pharmacol Res. 2016; 107:352-359.

24. Hanahan D, Weinberg RA. Hallmarks of cancer: the next generation. Cell. 2011; 144:646-74.

25. Chen YX, Zhong XY, Qin YF, Bing W, He LZ. 15d-PGJ2 inhibits cell growth and induces apoptosis of MCG-803 human gastric cancer cell line. World J Gastroenterol. 2003; 9:2149-53.

26. Ciucci A, Gianferretti P, Piva R, Guyot T, Snape TJ, Roberts SM, Santoro MG. Induction of apoptosis in estrogen receptor-negative breast cancer cells by natural and synthetic cyclopentenones: role of the IkappaB kinase/ nuclear factor-kappaB pathway. Mol Pharmacol. 2006; 70:1812-21.

27. Rosetti M, Frasnelli M, Fabbri F, Arienti C, Vannini I, Tesei A, Zoli W, Conti M. Pro-apoptotic activity of cyclopentenone in cancer cells. Anticancer Res. 2008; 28:315-20.

28. Kim DH, Song NY, Kim EH, Na HK, Joe Y, Chung HT, Surh YJ. 15-deoxy- $\Delta 12,14$-prostaglandin $\mathrm{J}_{2}$ induces p53 expression through Nrf2-mediated upregulation of heme oxygenase-1 in human breast cancer cells. Free Radic Res. 2014; 48:1018-27.

29. Koyani CN, Kitz K, Rossmann C, Bernhart E, Huber E, Trummer C, Windischhofer W, Sattler W, Malle E. Activation of the MAPK/Akt/Nrf2-Egr1/HO-1-GCLc axis protects MG-63 osteosarcoma cells against 15d-PGJ2mediated cell death. Biochem Pharmacol. 2016; 104:29-41.

30. Radi R, Cassina A, Hodara R. Nitric oxide and peroxynitrite interactions with mitochondria. Biol Chem. 2002; 383:401-9.

31. Lee YJ, Cho HN, Soh JW, Jhon GJ, Cho CK, Chung HY, Bae S, Lee SJ, Lee YS. Oxidative stress-induced apoptosis is mediated by ERK1/2 phosphorylation. Exp Cell Res. 2003; 291:251-66.

32. Monti M, Terzuoli E, Ziche M, Morbidelli L. The sulphydryl containing ACE inhibitor Zofenoprilat protects coronary endothelium from Doxorubicin-induced apoptosis. Pharmacol Res. 2013; 76:171-81.

33. Wada T, Penninger JM. Mitogen-activated protein kinases in apoptosis regulation. Oncogene. 2004; 23:2838-49.

34. Cagnol S, Chambard JC. ERK and cell death: mechanisms of ERK-induced cell death--apoptosis, autophagy and senescence. FEBS J. 2010; 277:2-21.

35. Zou H, Li Y, Liu X, Wang X. An APAF-1.cytochrome c multimeric complex is a functional apoptosome that activates procaspase-9. J Biol Chem. 1999; 274:11549-56.

36. Yasuda H. Solid tumor physiology and hypoxia-induced chemo/radio-resistance: novel strategy for cancer therapy: nitric oxide donor as a therapeutic enhancer. Nitric Oxide. 2008; 19:205-16.

37. Folkes LK, O'Neill P. DNA damage induced by nitric oxide during ionizing radiation is enhanced at replication. Nitric Oxide. 2013; 34:47-55.

38. Bonavida B, Garban H. Nitric oxide-mediated sensitization of resistant tumor cells to apoptosis by chemoimmunotherapeutics. Redox Biol. 2015; 6:486-94.

39. Carneiro ZA, de Moraes JC, Rodrigues FP, de Lima RG, Curti C, da Rocha ZN, Paulo M, Bendhack LM, Tedesco AC, Formiga AL, da Silva RS. Photocytotoxic activity of a nitrosylphthalocyanine ruthenium complex - a system capable of producing nitric oxide and singlet oxygen. J Inorg Biochem. 2011; 105:1035-43.

40. Carneiro ZA, Biazzotto JC, Alexiou AD, Nikolaou S. Nitric oxide photorelease from a trinuclear ruthenium nitrosyl 
complex and its in vitro cytotoxicity against melanoma cells. J Inorg Biochem. 2014; 134:36-8.

41. Calì B, Ceolin S, Ceriani F, Bortolozzi M, Agnellini AH, Zorzi V, Predonzani A, Bronte V, Molon B, Mammano F. Critical role of gap junction communication, calcium and nitric oxide signaling in bystander responses to focal photodynamic injury. Oncotarget. 2015; 6:10161-74. https://doi.org/10.18632/oncotarget.3553.

42. Yasuda H, Nakayama K, Watanabe M, Kaneta T, Asada M, Sasaki T, Yanagihara K, Yamaya M. Nitroglycerin may increase response to anticancer drugs in non-small cell lung cancer via reduction of HIF-1 $\alpha$ pathway. Nitric Oxide. 2007; 17:A24.

43. Ali AA, Coulter JA, Ogle CH, Migaud MM, Hirst DG, Robson T, McCarthy HO. The contribution of $\mathrm{N}_{2} \mathrm{O}_{3}$ to the cytotoxicity of the nitric oxide donor DETA/NO: an emerging role for S-nitrosylation. Biosci Rep. 2013; 33.

44. Tan BJ, Chiu GN. Role of oxidative stress, endoplasmic reticulum stress and ERK activation in triptolide-induced apoptosis. Int J Oncol. 2013; 42:1605-12.

45. Carvalho H, Evelson P, Sigaud S, Gonzalez-Flecha B. Mitogen-activated protein kinases modulate $\mathrm{H}(2) \mathrm{O}(2)$ induced apoptosis in primary rat alveolar epithelial cells. $\mathrm{J}$ Cell Biochem. 2004; 92:502-13.

46. Zhuang S, Schnellmann RG. A death-promoting role for extracellular signal-regulated kinase. J Pharmacol Exp Ther. 2006; 319:991-7.

47. Javvadi P, Segan AT, Tuttle SW, Koumenis C. The chemopreventive agent curcumin is a potent radiosensitizer of human cervical tumor cells via increased reactive oxygen species production and overactivation of the mitogenactivated protein kinase pathway. Mol Pharmacol. 2008; 73:1491-501.

48. Wang F, Sekine H, Kikuchi Y, Takasaki C, Miura C, Heiwa O, Shuin T, Fujii-Kuriyama Y, Sogawa K. HIF-1alphaprolyl hydroxylase: molecular target of nitric oxide in the hypoxic signal transduction pathway. Biochem Biophys Res Commun. 2002; 295:657-62.

49. Nabeyrat E, Jones GE, Fenwick PS, Barnes PJ, Donnelly LE. Mitogen-activated protein kinases mediate peroxynitrite-induced cell death in human bronchial epithelial cells. Am J Physiol Lung Cell Mol Physiol. 2003; 284:L1112-20.

50. Murphy PJ, Galigniana MD, Morishima Y, Harrell JM, Kwok RP, Ljungman M, Pratt WB. Pifithrin-alpha inhibits p53 signaling after interaction of the tumor suppressor protein with hsp90 and its nuclear translocation. J Biol Chem. 2004; 279:30195-201.

51. Donnini S, Monti M, Castagnini C, Solito R, Botta M, Schenone S, Giachetti A, Ziche M. Pyrazolo-pyrimidinederived c-Src inhibitor reduces angiogenesis and survival of squamous carcinoma cells by suppressing vascular endothelial growth factor production and signaling. Int $\mathbf{J}$ Cancer. 2007; 120:995-1004.

52. Donnini S, Finetti F, Solito R, Terzuoli E, Sacchetti A, Morbidelli L, Patrignani P, Ziche M. EP2 prostanoid receptor promotes squamous cell carcinoma growth through epidermal growth factor receptor transactivation and iNOS and ERK1/2 pathways. FASEB J. 2007; 21:2418-30.

53. Kim EH, Surh YJ. The role of 15-deoxy- $\Delta 12,14-$ prostaglandin $\mathrm{J} 2$, an endogenous ligand of peroxisome proliferator-activated receptor $\gamma$, in tumor angiogenesis. Biochem Pharmacol. 2008;76:1544-53.

54. Bishop-Bailey D, Hla T. Endothelial cell apoptosis induced by the peroxisome proliferator-activated receptor (PPAR) ligand 15-deoxy-Delta12, 14-prostaglandin J2. J Biol Chem. 1999; 274:17042-8.

55. Parinandi NL, Sharma A, Eubank TD, Kaufman BF, Kutala VK, Marsh CB, Ignarro LJ, Kuppusamy P. Nitroaspirin (NCX-4016), an NO donor, is antiangiogenic through induction of loss of redox-dependent viability and cytoskeletal reorganization in endothelial cells. Antioxid Redox Signal. 2007; 9:1837-49.

56. Dong R, Wang X, Wang H, Liu Z, Liu J, Saavedra JE. Effects of JS-K, a novel anti-cancer nitric oxide prodrug, on gene expression in human hepatoma Hep3B cells. Biomed Pharmacother. 2017; 88:367-373.

57. Arrieta O, Blake M, de la Mata-Moya MD, Corona F, Turcott J, Orta D, Alexander-Alatorre J, Gallardo-Rincón D. Phase II study. Concurrent chemotherapy and radiotherapy with nitroglycerin in locally advanced non-small cell lung cancer. Radiother Oncol. 2014; 111:311-5.

58. Yasuda H, Yamaya M, Nakayama K, Sasaki T, Ebihara S, Kanda A, Asada M, Inoue D, Suzuki T, Okazaki T, Takahashi H, Yoshida M, Kaneta T, et al. Phase II trial comparing nitroglycerin plus vinorelbine and cisplatin with vinorelbine and cisplatin alone in previously untreated stage IIIB/IV non-small-cell lung cancer. J Clin Oncol. 2006;24:688-94.

59. Terzuoli E, Finetti F, Costanza F, Giachetti A, Ziche M, Donnini S. Linking of mPGES-1 and iNOS activates stemlike phenotype in EGFR-driven epithelial tumor cells. Nitric Oxide. 2017; 66:17-29.

60. Ciccone V, Monti M, Antonini G, Mattoli L, Burico M, Marini F, Maidecchi A, Morbidelli L. Efficacy of AdipoDren $^{\circledR}$ in reducing interleukin-1-induced lymphatic endothelial hyperpermeability. J Vasc Res 2016; 53:255-268.

61. Monti M, Donnini S, Morbidelli L, Giachetti A, MochlyRosen D, Mignatti P, Ziche M. PKC $\varepsilon$ activation promotes FGF-2 exocytosis and induces endothelial cell proliferation and sprouting. J Mol Cell Cardiol. 2013; 63:107-17. 